IP Periodica Polytechnica

Transportation Engineering

47(1), pp. 29-35, 2019

https://doi.org/10.3311/PPtr.9992

Creative Commons Attribution (i)

RESEARCH ARTICLE

\section{Optimization of Work Zone Segments on Urban Roads Using Cellular Automata Model in Mixed Traffic}

\author{
Mohit Kumar Singh ${ }^{1}$, Gaurav Pandey ${ }^{1}$, K. Ramachandra Rao ${ }^{2 *}$
}

Received 07 September 2016; accepted 03 July 2017

\begin{abstract}
Increased delays and reduced speeds in work zones leads to congestion. This can be improved by optimizing the work zone length. The focus of this study is to model work zones using cellular automata model and to find the effects of work zones on traffic flow. The methodology adopted in the study involved creating work-zone on the road by blocking some of the cells and then determining traffic characteristics such as delay and queue lengths for model validation. For this the lateral movement rules of the existing Cellular Automata model were modified in order to replicate the traffic movement near work zones. This model is calibrated and validated using data from work zone observed near a metro rail station in Delhi. From the analysis it was evident that the queue length increased with increase in the length of work zone. Several relationships were tried between delay and work zone length. Among them the rational form was found suitable.
\end{abstract}

\section{Keywords}

heterogeneous traffic, Work zone, Cellular automata, delay, queue, calibration, validation

\footnotetext{
${ }^{1}$ Department of Civil Engineering, Indian Institute of Technology Delhi, New Delhi 110016 India

${ }^{2}$ Department of Civil Engineering and Transportation Research and Injury Prevention Programme (TRIPP), Indian Institute of Technology Delhi, New Delhi 110016 India

*Corresponding author, e-mail: rrkalaga@civil.iitd.ac.in
}

\section{Introduction}

Any construction or maintenance area on a highway is called work zone (Highway Capacity Manual, 2010). Work zone length (L) affects the traffic movement resulting in delays, congestion and accidents. A study by Schonfeld and Chein (1999) shows that delay costs increase with increase in work zones length and maintenance of pavement can be done in several steps. In a good traffic management system travellers should face less delay and safety should also be ensured (Jiang and Adeli, 2004). Hence a good strategy for deciding work zone length can reduce traveller's delay time and congestion.

Recently some researchers have explored the idea of using traffic flow simulation models in determining optimum work zone lengths (Marzouk and Fouad, 2014). Mathematical models of traffic flow are complicated so simulation of traffic is adopted by most of the researchers (Mathew et al., 2006). Some microscopic simulation tools can represent nearly actual traffic flow such as CORSIM, but these softwares need more execution time and high computational capability (Meng and Weng, 2010). Meng and Weng (2011) simulated a model of work zone considering two modes of traffic, but in reality there are multiple modes on the road.

Cellular automata (CA) models are widely used in simulation of traffic. There are few examples (Held and Bittihn, 2011; Li et al., 2012; Tian, 2012; Jin et al., 2014) in which authors used CA at intersections, while other few examples of CA used at several facilities such as roundabout, midblock and pedestrian streets $(\mathrm{Li}$ et al., 2016; Wang and Chen, 2016; Zhao et al., 2016; Heeroo et al., 2016). CA models are discrete, dynamic and computationally less cumbersome and require few sets of rules to operate. Besides, these models are flexible enough to incorporate multiple vehicle types and can simulate various conditions (Mallikarjuna and Rao, 2009). Thus CA model is preferred in this study.

In the present study, a CA model was developed to replicate the characteristics of a work zone in heterogeneous traffic environment and the effect of varying work zone lengths on delays were studied. A relationship was developed between work zone length and delays and then using the same relationship delays were minimized to find the optimal work zone length. 
Rest of the paper is organised as follows. Literature review for the work zone optimization using simulation is presented in Section 2. Section 3 discusses the methodology adopted in the study for data collection, simulation and optimization. Section 4 gives the analysis results obtained from the model. Section 5 concludes the study with future scope.

\section{Work zone optimization using simulation}

Nagel and Schreckenberg (NaSch) model (Nagel and Schreckenberg, 1992) is the first of its kind in the simulation models developed using $\mathrm{CA}$. NaSch model simulates single lane homogenous traffic with certain longitudinal movement rules using CA after this many models were proposed based on NaSch model. Larraga et al. (2005) simulated a single lane traffic model and added some modifications to NaSch model (mainly safety distance parameter). When the safety distance parameter becomes equal to ' 1 ' then this model would become NaSch model. A single lane traffic simulation cannot replicate realistic traffic so multilane traffic simulation models were developed. Later other authors (Meng and Weng, 2010; Wagner et al., 1997; Jia et al., 2005) came up with a multilane homogeneous traffic model. Although multilane models are close to realistic traffic but do not replicate real traffic behaviour as traffic is mostly heterogeneous. Authors (Lan and Chang, 2005; Vasic and Ruskin, 2012) developed models with two modes of traffic for multilane traffic flow. Subsequently many developments have taken place with the introduction of several modes of traffic to simulate various kinds of traffic flow situations (Mathew et al., 2006; Meng and Weng, 2011; Mallikarjuna and Rao, 2009). To consider natural human behaviour in simulation model randomization parameter is used, this parameter includes situations in which driver reduces the speed for example some incidents on road that diverts drivers attention. NaSch model and models before Gundaliya et al. (2008) have used a hypothetical value of randomization parameter. This parameter was first calibrated by Gundaliya et al. (2008) in normal traffic, later Meng and Weng (2010) calibrated it in a work zone. Rickert et al. (1996) implemented lane changing rules on NaSch model. Rickert et al. (1996) have defined two lane changing models, a) Symmetric model and b) Asymmetric model. In symmetric model, if a vehicle sees some other vehicle before it then follower vehicle will try to change lane and it will remain in the same lane (new changed lane) after changing lane until another vehicle comes before this vehicle. In asymmetric model a vehicle tries to remain in the inner lane if a vehicle comes before it then it changes the lane and after changing the lane it again comes in the same lane. Subsequently Chowdhury et al. (1997) proved that asymmetric lane changing model replicates realistic traffic behaviour more accurately. Later Meng and Weng (2011) also introduced lane changing rules based on safety and incentive criteria.

In the context of work zone analysis, a study by Schonfeld and Chien (1999) shows that delay cost increases with increase in work zone length. So delay can be optimized by minimizing the work zone length. They optimized work zone length for two lane highways. Later Chien and Schonfeld (2001) optimized work zone length for four lane highways. Both these study use mathematical approach to develop a relation between work zone length and total cost (including delay cost, agency cost and accident cost). Following is the relation developed by Chien and Schonfeld (2001)

$$
\text { Optimum Work Zone Length }=\sqrt{\frac{2 z_{1}+p_{1} p_{2} p_{3} z_{3}^{2}}{p_{1} p_{2} p_{3} z_{4}^{2}+p_{4} z_{4}^{2} c_{w} c_{z}}}
$$

Where $\mathrm{p}_{1}, \mathrm{p}_{2}, \mathrm{p}_{3}, \mathrm{p}_{4}$ are parameters and $\mathrm{z}_{1}, \mathrm{z}_{3}$ and $\mathrm{z}_{4}$ are different costs like delay cost, agency cost and accident cost etc. $\mathrm{c}_{\mathrm{w}}$ is capacity of road.

Present model uses three different situations randomization parameter and asymmetric lane rules with work zone. Randomization parameters were calibrated with field data by Mallikarjuna and Rao (2009). As it is evident from the literature review that among all of the heterogeneous traffic models proposed, very few of them can simulate traffic on work zones. Hence there is a need to develop a work zone simulation model so that it can be used to determine optimum work zone length and traffic movement strategies for minimizing delay and maximize the safety of road users. The present study attempts to improve the safety on work zones as it is known that high speeds and lane changing induced due to work zone is one of the main causes of crashes.

\section{Methodology}

Fig. 1 presents the steps of the methodology of the study.

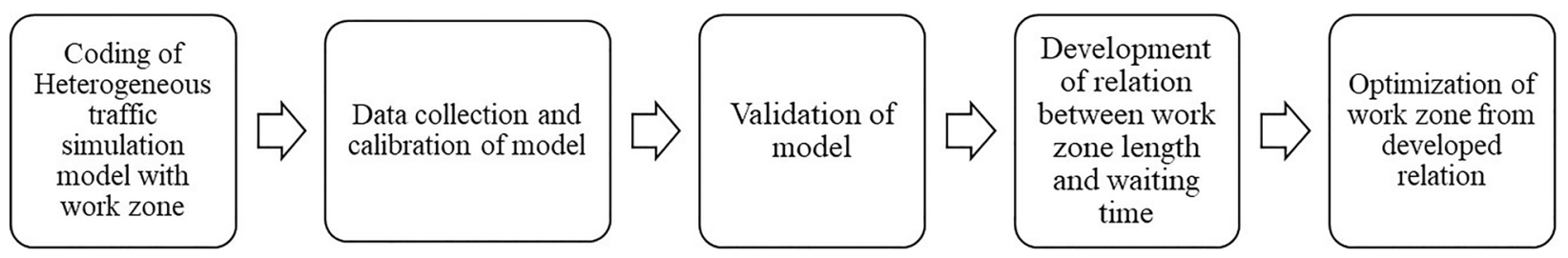

Fig. 1 Methodology of the study 


\subsection{Simulation}

A cellular automata model developed by Mallikarjuna and Rao (2009) was adopted for the study as it was found to adequately describe multilane heterogeneous traffic in India. The model adopts cellular automata brake light model for heterogeneous traffic conditions in India. The model represents Indian traffic conditions and is validated both at macroscopic level using fundamental diagrams and microscopic level using interaction rate between individual vehicle types. Hence this model was selected for simulation and necessary modifications were made in the algorithm to enable the creation of work zones on a lattice. The algorithm was developed using object oriented programming in MATLAB ${ }^{\circledR}$ to simulate traffic using $C A$ model and a work zones were created by blocking certain cells on the lattice. Fig. 2 shows the adopted simulation methodology.

While running the simulation it takes some time to replicate the real traffic conditions. In the present study simulation was run for 1000 times to allow the model to stabilize out of which initial 500 runs were discarded. The road width was taken as $3.5 \mathrm{~m}$ per lane. Road width was divided into $0.7 \mathrm{~m}$ (width) $\times$ $0.5 \mathrm{~m}$ (length). Thus a road made of 10 cells in lateral direction, in longitudinal direction $500 \mathrm{~m}$ road, array of 1000 cells was formed. Using this cell size all vehicles pertinent to heterogeneous traffic conditions can be represented more accurately (Mallikarjuna and Rao, 2009).

The lateral and longitudinal movement rules used in this study are presented here:

\section{Randomization parameter:}

Most of the previous studies have used single randomization parameter while the present study uses three randomization parameters based on vehicle speed and available gaps.

If (current speed $>0$ \& current leader status $==1 \&$ effective gap) <=interaction headway)

randomization parameter $=p_{b}$

$$
\begin{aligned}
& \text { If current speed }=0 \\
& \quad \text { randomization parameter }=p_{0} \\
& \text { Else randomization parameter }=p_{d e c}
\end{aligned}
$$

\section{Acceleration:}

Acceleration of a vehicle will depend upon the available gaps and minimum required gaps to accelerate.

If current leader status status $=0 \quad \|$ effectivegap $>=$ interactionheadway

currentspeed $=\min ($ currentspeed + acceleration, Maxspeed $)$;

\section{Deceleration:}

Vehicle will decelerate according to the effective available gap. If less gap is available then vehicle will adopt a speed which will be the minimum of current speed or available gap.

currentspeed $=$ min (current speed, effective gap);

\section{Randomization}

A random number will be generated in each loop and will be compared with randomization parameter, and speed will be updated accordingly.

$$
p 1=\text { rand; }
$$

\section{If $p 1<$ randomization parameter}

if (randomization parameter $=p_{b l} \|$ randomization parameter $=p_{o}$ )

$$
\begin{aligned}
& \text { currentspeed }=\max (\text { current speed-acceleration, } 0) \text {; } \\
& \text { elseif (randomization parameter }=p_{\text {ded }} \text { ) }
\end{aligned}
$$$$
\text { currentspeed }=\max (\text { currentspeed }-1,0) \text {; }
$$

\section{Car motion:}

Finally a vehicle will move to the new position $\left(x_{n(t+1)}\right)$ according to the updated speed $\left(v_{n(t+1)}\right)$ speed and previous location $\left(v_{n(t+1)}\right)$.

$$
x_{n(t+1)}=x_{n(t)}+v_{n(t+1)}
$$

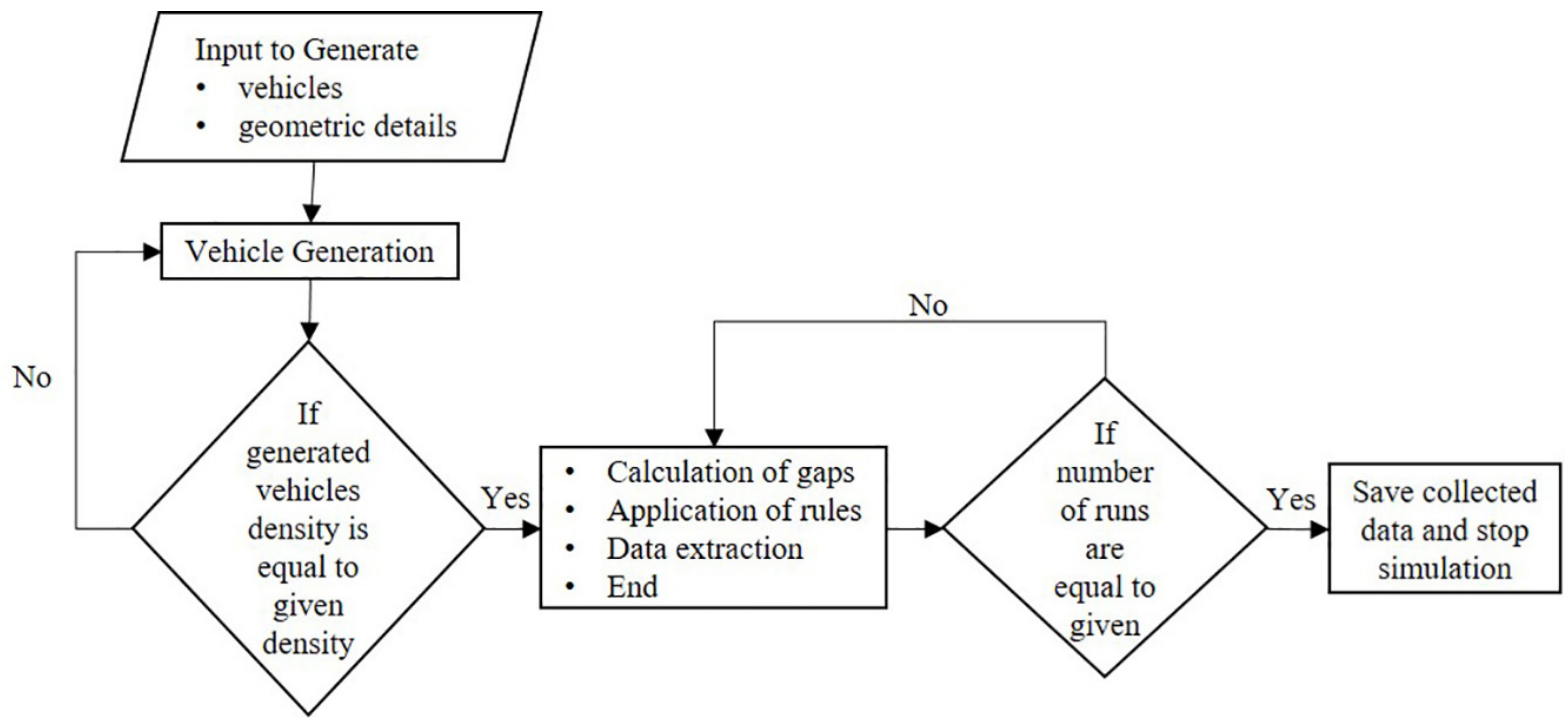

Fig. 2 Algorithm for Multi lane Simulation model 


\section{Lane changing Rules:}

Following lane changing rules are applied in the current model.

\section{Incentive criterion}

When following driver want to change the lane for example to overtake the leader vehicle, then leader incentive criterion is taken into consideration. If a vehicle is accelerating with some speed and gap available is insufficient to cross the leader vehicle then the follower vehicle will change the lane. Similarly if a vehicle with some acceleration has speed more than leader vehicle then in this case also, follower will change the lane.

1. $\left(v_{n}+a_{n}\right)>g_{n}$

2. $\left(v_{n}+a_{n}\right)>v_{n+1}$

' $v_{n}$ ' is the speed of following vehicle and ' $a_{n}$ ' is the acceleration of following vehicle ' $v_{n+1}$ ' is speed of leader vehicle, ' $g_{n}$ ' is available gap between following an leader vehicle.

\section{Safety criteria}

Safety criteria mainly depend on the gaps available. A parameter ' $\alpha$ ' was defined to check the sufficient gap available to change the lane safely. If the available gap between following and leader vehicle $\left(g_{n, o f}\right)$ were greater than ' $\alpha$ ' times speed then following vehicle should change the speed.

$$
g_{n, o, f}>\alpha * v_{n}
$$

After the development of model several relationships were tried for fitting the work zone length and waiting time relation in simulated data and it was found that rational relation to be a good candidate. Eq. (1) was further used for optimization. Simple calculus was applied to find the minimum waiting time. This relationship was differentiated with respect to the work zone length and equated to zero to get a minimum value of the waiting time. Following parameters (Table 1) were taken in the model. These parameters were calibrated by Mallikarjuna and Rao (2009).

Further for calibration of model from field data flow of traffic was counted manually for each minute from the video. Flow and density observed from video data was then converted into the hourly data. This method of extracting data was adopted from a study by Hourdakis et al. (2003).

\subsection{Data collection and Extraction}

Data used for calibration and validation was taken from field directly. INA metro station in Delhi India was chosen as data collection site. This site had an $85 \mathrm{~m}$ work zone and around $2200 \mathrm{veh} / \mathrm{hr}$ flow. Two hours traffic data was collected using video cameras between 8 to $10 \mathrm{AM}$ in March 2015. Spot speeds of vehicles were recorded using speed guns (Lidar Gun) at each minute interval. These recorded speeds were then converted into space mean speeds using the Eq. (2). The layout of data collection location is shown in Fig. 3.
Table 1 Simulation parameters

\begin{tabular}{lllll}
\hline Parameters & Car $(\mathrm{MV})$ & $\begin{array}{l}\text { Two } \\
\text { Wheeler }\end{array}$ & $\begin{array}{l}\text { Three } \\
\text { Wheeler }\end{array}$ & Truck $(\mathrm{T})$ \\
\hline Length & 7 cells $(3.5 \mathrm{~m})$ & 4 cells $(2 \mathrm{~m})$ & 6 cells $(3 \mathrm{~m})$ & 25 cells $(12.5 \mathrm{~m})$ \\
Width & 3 cells $(2.1 \mathrm{~m})$ & 1 cells $(0.7 \mathrm{~m})$ & 2 cells $(1.4 \mathrm{~m})$ & 4 cells $(2.8 \mathrm{~m})$ \\
Maximum & 30 & 26 & 20 & 28 \\
Speed & & 5 & 2 & 2 \\
Acceleration & 4 & 0.3 & 0.4 & 0.6 \\
$\mathrm{p}_{\mathrm{o}}$ & 0.5 & 0.1 & 0.3 & 0.1 \\
$\mathrm{p}_{\text {dec }}$ & 0.3 & 1.5 & 2 & 1.5 \\
$\alpha$ & 1 & 0.94 & 0.94 & 0.94 \\
$\mathrm{p}_{\mathrm{b}}$ & 0.94 & 0.5 & 0.5 & 0.5 \\
$\mathrm{p}_{1}$ & 0.5 & 2 & 5 & 6 \\
$\begin{array}{l}\text { Security } \\
\text { Distance }\end{array}$ & 5 & 6 & 6 & 21 \\
$\begin{array}{l}\text { Interaction } \\
\text { headway }\end{array}$ & 6 & & 5 & \\
\hline
\end{tabular}

Here ' $\mathrm{q}$ ' is flow and ' $\mathrm{v}$ ' is time mean speed of vehicles

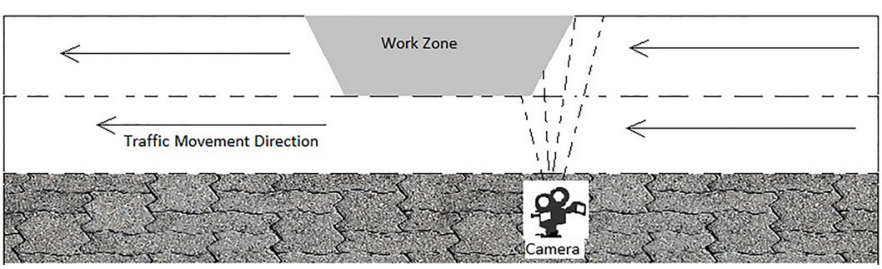

Fig. 3 Work Zone With camera locations at INA metro station Delhi for measuring flow

As the speeds recorded by speed gun are instantaneous speeds (time mean speeds are the arithmetic means of these speeds) and the basic relationship between speed (v), flow (q) and density $(\mathrm{k})(\mathrm{q}=\mathrm{kv})$ uses speeds as space mean speeds and hence there was need to convert the time mean speeds into space mean speeds. Eq. (2) was used to convert time mean speed to space speed:

$$
\text { Space mean speed }=\frac{\sum q_{i}}{\sum \frac{q_{i}}{v_{i}}}
$$

In collected data around $61 \%$ of the vehicles were cars, $22 \%$ were two wheelers, $13 \%$ were three wheelers and $4 \%$ were trucks. To compare the traffic characteristics (q-k-v) all vehicles are converted into same vehicle units using passenger car equivalents. Following values (Table 2) from Indian Road Congress (IRC) 106-1990 (Indian Roads Congress, n.d.) were used to convert passenger car equivalencies of vehicles: 
Table 2 PCU units of vehicles used

\begin{tabular}{ll}
\hline MODE & PCU \\
\hline Car & 1.00 \\
$2 \mathrm{~W}$ & 0.75 \\
$3 \mathrm{~W}$ & 2.00 \\
Truck & 2.20 \\
\hline
\end{tabular}

\subsection{Optimization}

The trends presented in Fig $4 \mathrm{a}$ and $4 \mathrm{~b}$ have been observed by varying work zone length and waiting time of individual vehicles. Fig. $4 \mathrm{a}$ is a fit of second degree polynomial, while Fig. 4b is a rational fit of the work zone length and waiting time.

Second degree polynomial relation of work zone length and waiting time (Fig. 4a) is as follows:

(a)
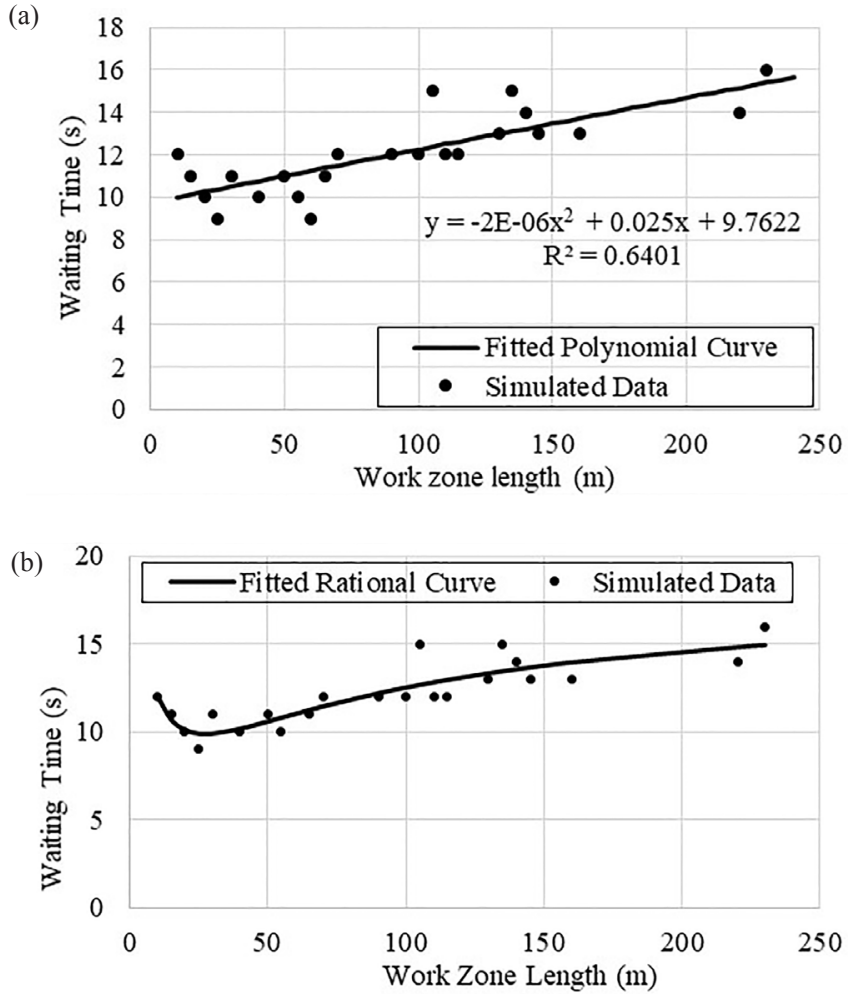

Fig. 4 Work Zone Length vs. Waiting Time

The Eq. (3) resulting from the data trend line is shown below

Waiting time $=-2 \times 10^{-6} L^{2}+0.025 \times L+9.7622$

Fig. $4 \mathrm{~b}$ is fitted using MATLAB $\AA$. Rational equation of Fig. $4 \mathrm{~b}$ is as follows:

$$
\text { Delay }=\frac{p_{1} L^{2}+p_{2} L+C p_{3}}{L^{2}+p_{4} L+p_{5}}
$$

$p_{1}, p_{2}, p_{3}, p_{4}, p_{5}$ can be treated as parameters and ' $C$ ' is the capacity of the highway.

For minimum Delay: Keeping values of $p_{1}, p_{2}, p_{3}, p_{4}, p_{5}$ and $C$ in Eq. (5) and equating to zero

$$
\begin{gathered}
\frac{d D}{d L}=\frac{\left(L^{2}+p_{4} L+p_{5}\right)\left(p_{2}+2 p_{1} L\right)-\left(p_{1} L^{2}+p_{2} L+C p_{3}\right)\left(p_{4}+2 L\right)}{\left(L^{2}+p_{4} L+p_{5}\right)^{2}} \\
\frac{d D}{d L}=0 \\
\left(L^{2}+p_{4} L+p_{5}\right)\left(p_{2}+2 p_{1} L\right)-\left(p_{1} L^{2}+p_{2} L+C p_{3}\right)\left(p_{4}+2 L\right)=0
\end{gathered}
$$

Eq. (8) was solved using MATLAB $\AA$ for optimized work zone length.

$$
L^{2}\left(p_{1} p_{4}-p_{2}\right)+2 L\left(p_{1} p_{5}-2 C p_{3}\right)+p_{2} p_{5}=0
$$

\section{Analysis of results}

The results are analysed by looking the outputs of the simulation model. Calibration of the model was carried out with speed. Mean Absolute Percentage Error (MAPE), the error between predicted speed and measured speed was calculated and found 19.21.

Data can be validated using visual interpretation of field and simulated data [29]. Figs. 5-7 shows the relation between flow and density values obtained from the CA model and the field data.

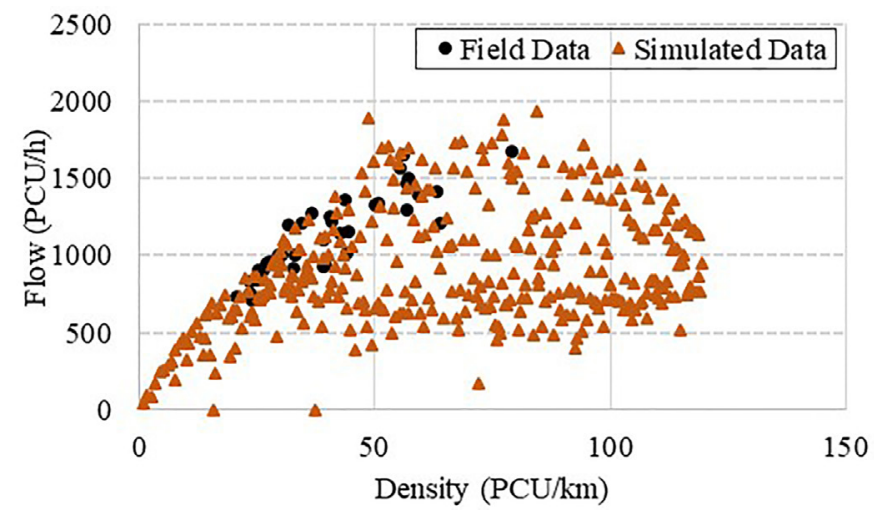

Fig. 5 Density vs Flow

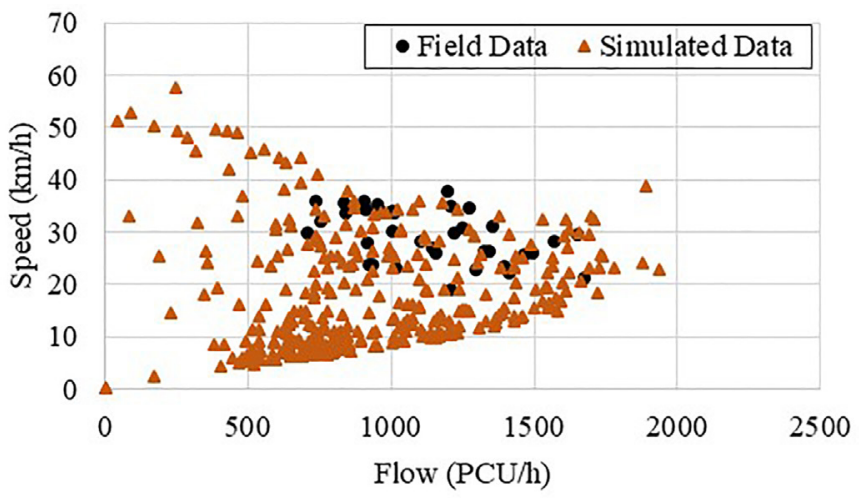

Fig. 6 Flow vs. Speed 


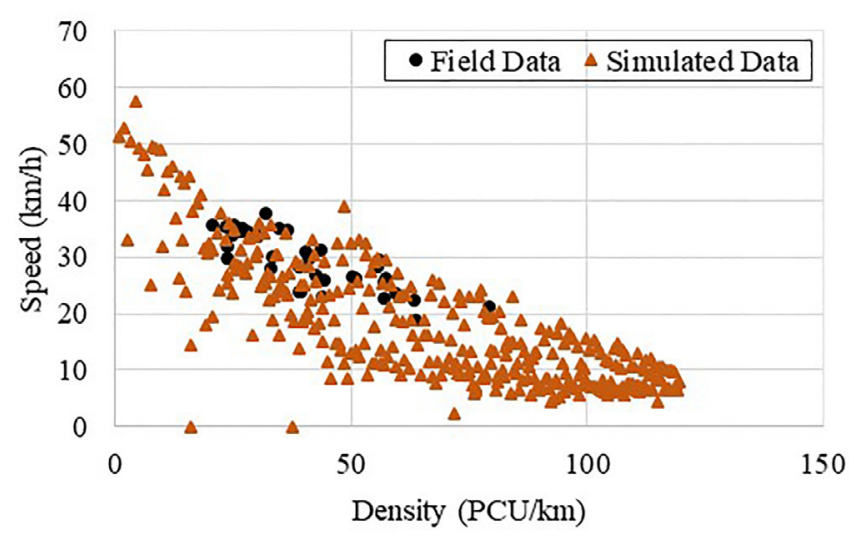

Fig. 7 Density vs Speed

In above curves if simulated points are visualised then these curves are similar to the fundamental flow, density speed (q-kv) curves, hence simulation data is validated with fundamental curves. Again from the trend of the above three curves it can be seen that these curves are matching with the field data hence simulated data represents field data effectively. Field traffic is mostly in uncongested state hence only the left side of curves corresponding to free flow portion is present.

To optimize the work zone length, when variation of work zone length and waiting time was fitted in second order polynomial (Fig. 4a) variation is having R-square of 0.64. In Fig. 4a it can be observed that waiting time is increasing with increase in work zone length. Due to a low parameter value of second degree term in the fit equation of Fig. 4a this looks like constantly increasing linear curve (as in Eq. (3)). This is as expected and described in earlier studies (Schonfeld and Chein, 1999). Again to get a closer relation between work zone length and waiting time another relationship was tried. With an R-square value (Fig. 4b) of 0.76 and SSE of 16.53 a rational relation Eq. (4) was developed. Mathematical relations by Schonfeld and Chien (1999) and by Chien and Schonfeld (2001) shows curve behaviour similar to the one shown in Fig. 4b. Due to the higher explanatory power than polynomial fit, rational curve was adopted. Eq. (4) and Eq. (8) were solved using MATLAB ${ }^{\circledR}$ to get an optimized work zone length (L) of $27.47 \mathrm{~m}$.

Chien and Schonfeld (2001) found an optimized work zone length of $1.4 \mathrm{~km}$ including others costs such as delay cost, agency cost and accident cost etc. Another study by Jiang and Adeli (2004) described optimal work zone length varying from $0.2 \mathrm{~km}$ to $0.55 \mathrm{~km}$ based upon the different time of the day. Jiang and Adeli (2004) also considered user delay, accident, and maintenance costs. The present study takes into account the waiting time only while the other parameters such as maintenance or accident cost were not considered. These costs cannot be predicted by the present traffic flow simulation model and hence they were not used in the optimization model. This could be a reason for the difference in length of optimized work zone as compared to other studies.

\section{Conclusions}

1. From the analysis it can be concluded that the simulation model represents the field traffic conditions satisfactorily. The fundamental diagrams ( $\mathrm{q}-\mathrm{k}-\mathrm{v}$ ) developed from cellular automata model were similar to those presented in the Highway Capacity Manual (2010).

2. In addition to the delays, the model could also be used to determine maximum queue lengths. The result shows that the q-k-v (fundamental diagrams) diagrams obtained from the simulation are nearly matching with the field values.

3. The optimization of work zone length is carried out by developing a relationship between work zone lengths and waiting time of the vehicles. Rational model found to be best fitted model for waiting time and work zone length.

4. A strong relationship is observed between work zone length and delays with R-square value of 0.76 with SSE of 16.53. The estimated optimized work zone length obtained from the present study is $27.47 \mathrm{~m}$. As the work zone length vary for different field conditions, this model can be applied after proper calibration.

5. Only one constraint is considered to optimize the work zone length in the present study. In future study, other factors such as maintenance cost and initial cost will be considered to improve the model further.

\section{References}

Chien, S., Schonfeld, P., Chien, B. S., Schonfeld, P. (2001). Optimal Work Zone Lengths for Four-Lane Highways. Journal of Transportation Engineering. 127(2), pp. 124-131.

https://doi.org/10.1061/(ASCE)0733-947X(2001)127:2(124)

Chowdhury, D., Wolf, D. E., Schreckenberg, M. (1997). Particle hopping models for two-lane traffic with two kinds of vehicles: Effects of lanechanging rules. Physica A: Statistical Mechanics and its Applications. 235(3-4), pp. 417-439.

https://doi.org/10.1016/S0378-4371(96)00314-7

Daamen, W., Buisson, C., Hoogendoorn, P. S. (2015). Traffic Simulation and Data Validation Methods and Applications. Taylor \& Francis Group, Boca Raton London New York.

Gundaliya, P. J., Mathew, T. V., Dhingra, S. L. (2008). Heterogeneous traffic flow modelling for an arterial using grid based approach. Journal of Advanced Transportation. 42(4), pp. 467-491. https://doi.org/10.1002/atr.5670420404

Heeroo, K. N. S., Gukhool, O., Hoorpah, D. (2016). A Ludo Cellular Automata model for microscopic traffic flow. Journal of Computational Science. 16, pp. $114-127$.

https://doi.org/10.1016/j.jocs.2016.04.015

Held, T., Bittihn, S. (2011). Cellular automata for traffic simulation Nagel-Schreckenberg model. Bonn. [Online]. Available from: http://www.iskp.uni-bonn. de/uploads/media/traffic.pdf [Accessed: 15th February 2015]

Highway Capacity Manual, (HCM) (2010) Washington, D.C.

Hourdakis, J., Michalopoulos, P., Kottommannil, J. (2003). Practical Procedure for Calibrating Microscopic Traffic Simulation Models. Transportation Research Record: Journal of the Transportation Research Board. 1852, pp. $130-139$. https://doi.org/10.3141/1852-17 
Indian Roads Congress. (n.d.) Guidelines for Capacity of Urban Roads in Plain Areas. New Dehi.

Jia, B., Jiang, R., Wu, Q.-S., Hu, M. (2005). Honk effect in the two-lane cellular automaton model for traffic flow. Physica A: Statistical Mechanics and its Applications. 348, pp. 544-552.

https://doi.org/10.1016/j.physa.2004.09.034

Jiang, X., Adeli, H. (2004). Object-Oriented Model for Freeway Work Zone Capacity and Queue Delay Estimation. Computer-Aided Civil and Infrastructure Engineering. 19(2), pp. 144-156. https://doi.org/10.1111/j.1467-8667.2004.00344.x

Jin, C.-J., Wang, W., Jiang, R., Wang, H. (2014). Cellular automaton simulations of a four-leg intersection with two-phase signalization. International Journal of Modern Physics C. 25(3), pp. 1350099. https://doi.org/10.1142/S012918311350099X

Lan, L. W., Chang, C.-W. (2005). Inhomogeneous cellular automata modeling for mixed traffic with cars and motorcycles. Journal of Advanced Transportation. 39(3), pp. 323-349. https://doi.org/10.1002/atr.5670390307

Li, X. X., Yan, X., Li, X. X., Wang, J. (2012). Using cellular automata to investigate pedestrian conflicts with vehicles in crosswalk at signalized intersection. Discrete Dynamics in Nature and Society. 2012(93), pp. 1-16. https://doi.org/10.1155/2012/287502

Li, Q. L., Wong, S. C., Min, J., Tian, S., Wang, B. H. (2016). A cellular automata traffic flow model considering the heterogeneity of acceleration and delay probability. Physica A: Statistical Mechanics and its Applications. 456, pp. 128-134.

https://doi.org/10.1016/j.physa.2016.03.026

Mallikarjuna, C., Rao, K. R. (2009). Cellular automata model for heterogeneous traffic. Journal of Advanced Transportation. 43(3), pp. 321-345. https://doi.org/10.1002/atr.5670430305

Marzouk, M., Fouad, M. (2014). Simulation-based model for optimizing highways resurfacing operations. The Baltic Journal of Road and Bridge Engineering. 9(1), pp. 58-65. https://doi.org/10.3846/bjrbe.2014.08

Mathew, T. V., Gundaliya, P., Dhingra, S. L. (2006). Heterogeneous Traffic Flow Modeling and Simulation Using Cellular Automata. In: Applications of Advanced Technology in Transportation. (pp. 492-497). American Society of Civil Engineers, Reston, VA.

https://doi.org/10.1061/40799(213)78

Meng, Q., Weng, J. (2010). Cellular Automata Model for Work Zone Traffic". Transportation Research Record: Journal of the Transportation Research Board. 2188(1), pp. 131-139.

https://doi.org/10.3141/2188-14
Meng, Q., Weng, J. (2011). An improved cellular automata model for heterogeneous work zone traffic. Transportation Research Part C: Emerging Technologies. 19(6), pp. 1263-1275.

https://doi.org/10.1016/j.trc.2011.02.011

Nagel, K., Schreckenberg, M. (1992). A cellular automaton model for freeway traffic. Journal de Physique I. 2(12), pp. 2221-2229.

https://doi.org/10.1051/jp1:1992277

R1, J. A., Lárraga, M. E., Río, J. a. Del, Alvarez-lcaza, L. (2005). Cellular automata for one-lane traffic flow modeling. Transportation Research Part C: Emerging Technologies. 13(1), pp. 63-74. https://doi.org/10.1016/j.trc.2004.12.001

Rickert, M., Nagel, K., Schreckenberg, M., Latour, A. (1996). Two lane traffic simulations using cellular automata. Physica A: Statistical Mechanics and its Applications. 231(4), pp. 534-550. https://doi.org/10.1016/0378-4371(95)00442-4

Schonfeld, P., Chien, S. (1999). Optimal Work Zone Lengths for Two-Lane Highways. Journal of Transportation Engineering. 125(1), pp. 21-29. https://doi.org/10.1061/(ASCE)0733-947X(1999)125:1(21)

Tian, L. (2012). Traffic Flow Simulation in a Scenario with Signalized Intersection and Bus Stop. Journal of Transportation Systems Engineering and Information Technology. 12(5), pp. 90-96. https://doi.org/10.1016/S1570-6672(11)60226-2

Vasic, J., Ruskin, H. J. (2012). Cellular automata simulation of traffic including cars and bicycles. Physica A: Statistical Mechanics and its Applications. 391(8), pp. 2720-2729.

https://doi.org/10.1016/j.physa.2011.12.018

Wagner, P., Nagel, K., Wolf, D. E. (1997). Realistic multi-lane traffic rules for cellular automata. Physica A: Statistical Mechanics and its Applications. 234(3-4), pp. 687-698.

https://doi.org/10.1016/S0378-4371(96)00308-1

Wang, Y., Chen, Y. Y. (2016). Modeling the effect of microscopic driving behaviors on Kerner's time-delayed traffic breakdown at traffic signal using cellular automata. Physica A: Statistical Mechanics and its Applications. 463, pp. 12-24.

https://doi.org/10.1016/j.physa.2016.06.126

Zhao, H.-T., Yang, S., Chen, X.-X. (2016). Cellular automata model for urban road traffic flow considering pedestrian crossing street. Physica A: Statistical Mechanics and its Applications. 462, pp. 1301-1313. https://doi.org/10.1016/j.physa.2016.06.146 